\title{
L-ARGININE, BUT NOT L-NAME PROTECTS AGAINST LIVER INJURY INDUCED BY EXPERIMENTAL ISCHEMIA-REPERFUSION
}

\author{
O. M. Oleshchuk, K. A. Posokhova, A. Ye. Mudra \\ I. YA. HORBACHEVSKY TERNOPIL STATE MEDICAL UNIVERSITY, TERNOPIL, UKRAINE
}

\begin{abstract}
Background. Hepatic ischemia-reperfusion $(I / R)$ injury occurs upon restoration of hepatic blood flow after a period of ischemia.

Objective. The study establishes that stimulation or blockade of nitric oxide synthesis has a protective effect during ischemia-reperfusion.

Methods. Male albino rats which were divided into four equal groups: sham-operated control, ischemia and reperfusion group (0.9 \% saline i.p.) for 3 days, group pre-treated with L-arginine (25 mg/kg i.p.), group pre-treated with L-NAME (10 mg/kg i.p.) for 3 days before ischemia-reperfusion maneuver. Complete ischemia of the median and left hepatic lobes was induced by clamping the left branches of the portal vein and the hepatic artery for $45 \mathrm{~min}$. Rats were sacrificed after 3-h reperfusion. Nitric oxide synthase 3 (endothelial) and nitric oxide synthase 2 (inducible) expression, nitric oxide stabile metabolites $\left(\mathrm{NO}_{2}, \mathrm{NO}_{3}\right)$ content, AST and ALT activities were determined. Histological examination of liver tissue was performed.

Conclusions. Relative NO deficiency, due to eNOS inhibition, is central in the pathogenesis of hepatic ischemia reperfusion injury. Replacing NO content with either precursors or via donor drugs represents novel methods in ameliorating ischemia-reperfusion injury.
\end{abstract}

KEY WORDS: hepatic ischemia-reperfusion, nitric oxide, NOS isoforms, L-arginine, L-NAME.

\section{Introduction}

Ischemia-reperfusion $(\mathrm{I} / \mathrm{R})$ of the liver is a complex of pathophysiological processes that occurs during surgery, trauma, liver transplantation and can lead to serious liver injury. Basic mechanisms of liver IR are not completely understood at present time, but we claim that reactive oxygen and nitrogen are important in this process. Overproduction of free radicals by activated Kupffer cells and neutrophils causes a number of toxic effects, including changes in lipid and protein oxidation, excretion of proinflammatory mediators and microvascular dysfunction, which together lead to cell and tissue damage [1]. According to Bahde H. (2010), the hepatic microcirculation violations and endothelial dysfunction also play main role in the pathophysiology of $\mathrm{I} /$ $R$ at the time of reperfusion [2]. The biologically active molecule of nitric oxide (NO) may play a pivotal role in the process of free radicals formation.

However, the data about the protective or damaging role of $\mathrm{NO}$ during $\mathrm{I} / \mathrm{R}$ are controversial. According to some studies the application of NO precursors minimizes the adverse effects of reperfusion and improves hepatic microcirculation $[3,4]$. On the other hand, studies of some researchers

Address for correspondence: Oleshchuk O.M., m. Voli, 1, Ternopil, 46001, Ukraine

Tel.: +380 352523987 . suggest that inhibitors of $\mathrm{NO}$ synthesis can prevent liver damage during $\mathrm{I} / \mathrm{R}$ [5].

This study shows that stimulation or blockade of nitric oxide synthesis has a protective effect during ischemia-reperfusion.

\section{Methods}

NO precursor - L-arginine and non-selective NOS blocker - L-NAME (N-nito-L-arginine methyl ester) were procured from Sigma; alanine aminotransferase (ALT) and aspartate aminotransferase (AST) kits were procured from "Filisit-diagnostic", while TNF- $\alpha$, IL-1 $1 \beta$, IL- 6 , eNOS, and iNOS ELISA kits were procured USCN Limited Inc.

Animal model

Male white rats (Ternopil State Medical University vivarium, Ukraine) 8 to 10 weeks old, were used for these experiments. All animals were fasted $12 \mathrm{~h}$ before experimentation and allowed water ad libitum. All animals received care in compliance with the "Guide for the Care and Use of Laboratory Animals" (National Institute of Health Publication № 85-23, revised 1985). The studies were carried out according to the National Institute of Health Guide for the Care and Use of Laboratory Animals and were approved by the local animal protection committee.

Induction of ischemic and reperfusion injury

The hepatic ischemia-reperfusion $(\mathrm{I} / \mathrm{R})$ protocols were performed as described in a previous study by Oleshchuk, 2012 [6]. There was no mortality 
observed associated with this model. The liver of each rat was exposed through a midline laparotomy after the induction of anesthesia (thiopental sodium $20 \mathrm{mg} / \mathrm{kg}$ i.p.). Complete ischemia of the median and left hepatic lobes was induced by clamping the left branches of the portal vein and the hepatic artery for $45 \mathrm{~min}$. The right hepatic lobe was perfused to prevent intestinal congestion. After the time frame sufficient for ischemia development, the ligatures around the left branches of the portal vein and hepatic artery were removed. In order to accurately evaluate the blood flow in the median and left hepatic lobes after ischemia, the right branches of the portal vein and the hepatic artery were ligated to prevent shunting to the right lobe after reperfusion and perfused for $2 \mathrm{~h}$. The wound was stitched with 3.0 silk suture. Sham-operated animals were similarly prepared except that no ligature was placed to obstruct the blood flow to the left and median hepatic lobes. Instead, it the blood flow to the right lobe of the liver was occluded. Rats were sacrificed in all groups after 1-h ischemia followed by 3-h reperfusion. Twenty four white rats were divided into four equal groups ( $n=6$ each group). Group 1 (shamoperated control group) and group 2 (ischemia and reperfusion group) were given $0.9 \%$ saline $(1 \mathrm{~mL} / \mathrm{kg}$, i.p.) for 3 days. Group 3 was pre-treated with L-arginine (25 mg/kg i.p.), group 4 - with L-NAME (10 mg/kg i.p.) for 3 days before, (last time $-10 \mathrm{~min}$ before) induced ischemia-reperfusion maneuver.

Peripheral blood and hepatic tissue procurement

Blood sampling for determination of liver enzymes. Blood samples were obtained from the right ventricle via left anterior thoracotomy at the time of sacrifice. Blood was collected in a sterile syringe without anticoagulant and centrifuged at $2000 \mathrm{~g}$ to separate the serum. The serum samples were stored at $-20^{\circ} \mathrm{C}$ until use for AST and ALT assays.

Blood sampling for cytokine and NOS determination. Serum was removed from blood samples by clotting for 2 hours on ice; serum was centrifuged at $2,500 \times \mathrm{g}\left(4^{\circ} \mathrm{C}\right)$, filtered, aliquoted, and frozen at $-20^{\circ} \mathrm{C}$ until assayed for $\mathrm{eNOS}$ and iNOS. Small liver samples were collected from each rat, then frozen immediately and stored in liquid nitrogen until used for eNOS and iNOS assays.

Determination of liver enzymes function

Determination of AST (EC 2.6.1.1) and ALT (EC 2.6.1.2) in plasma was performed by RaytmanFrenkel method, using a standard kit "Filisitdiagnostic" (Ukraine) according to the manufacturer's instructions. The activity of AST and ALT in serum were expressed in $\mathrm{mmol} /(\mathrm{L} \times \mathrm{h})$.

$\mathrm{NO}_{2}$ and $\mathrm{NO}_{3}$ assays.

$\mathrm{NO}_{2}$ and $\mathrm{NO}_{3}$ in serum of blood and liver homogenates $(1: 10)$ were determined as described by several authors [7].

\section{NOS assays}

Determination of eNOS activity was performed by ELISA method using "Enzyme-linked Immunosorbent Assay Kit for Rat Nitric Oxide Synthase 3, Endothelial (NOS3)", USCN, Life Science Inc, E90868Ra.

Determination of iNOS activity was done by ELISA method using "Enzyme-linked Immunosorbent Assay Kit for Rat Nitric Oxide Synthase 2, Inducible (NOS2)", USCN, Life Science Inc, E90837Ra.

eNOS and iNOS expression was investigated in blood plasma and liver tissue. Blood was collected using EDTA as an anticoagulant. Samples were centrifuged for $15 \mathrm{~min}$ at $1000 \mathrm{~g} / \mathrm{min}$ at $2-8^{\circ} \mathrm{C}$ within 30 min after collection. Determination was carried out immediately or frozen at $-20^{\circ} \mathrm{C}$.

The procedure of liver cells lysis was performed as follows:

1. Preparing liver homogenates in isotonic $\mathrm{NaCl}$ solution at a ratio of 1:10.

2. Liver cells were centrifuged for $5 \mathrm{~min}$ at $300 \mathrm{~g}$, and then the supernatant was removed.

3. Cells were washed twice with isotonic $\mathrm{NaCl}$ solution, after each wash the suspension was centrifuged at $300 \mathrm{~g}$ for $5 \mathrm{~min}$.

4. Buffer (PBS) was added to the normal liver tissue lysate ( $1 \mathrm{ml}$ of buffer at $1 \times 10^{6}$ liver cells). It was centrifuged for $5 \mathrm{~min}$ at $300 \mathrm{~g}$.

5. The supernatant was collected. Determination of enzyme activity was carried out immediately or the supernatant was frozen at $-20^{\circ} \mathrm{C}$.

Determination of eNOS and iNOS concentration were performed by ELISA method and according to the manufacturer's instruction. eNOS activity in serum and in hepatocytes ( $1 \mathrm{ml}-1 \times 10^{6}$ cells) was expressed as $\mathrm{U} / \mathrm{ml}$, and iNOS activity was expressed as $\mathrm{ng} / \mathrm{ml}$.

\section{Histopathology study}

A portion of the tissue from the ischemic liver lobe was fixed in $10 \%$ neutral-buffered formalin solution for 5 days, embedded in paraffin, and sectioned. The sections were stained with hematoxylin and eosin.

\section{Statistical analysis}

Statistical analysis was carried out by OriginPro Program. Results are expressed as mean \pm standard deviation. Differences between experimental groups were analyzed with an unpaired 2-tailed Student $t$ test. All differences were considered statistically significant at a $p<0.05$.

\section{Results}

The results indicate that after 45 min postischemia followed by $2 \mathrm{~h}$ reperfusion the activity of ALT in blood increased from $(0.44 \pm 0.10)$ in the sham control group compared to $(2.35 \pm 0.09)$ in l/R group 
animals, which is 5.3 times increase. Accordingly, AST activity increased from (1.63 \pm 0.12$)$ to $(4.27 \pm$ 0.37 ), which is 2.6 times increase. The described dynamics indicates that cytolysis process of hepatocytes is evolving under simulated IR injury (Table 1).

The significant increase in ALT and AST activities, that occurred in I/R group, was significantly suppressed by pre-treatment with $25 \mathrm{mg} / \mathrm{kg} \mathrm{L}$-arginine (Table 1). Thus, the transaminases activity was significantly lower: ALT (53.2\%) and AST (33.6\%). The activity of ALT and AST increased by $38 \%$ and $84 \%$ with the introduction of L-NAME compared to those of animals with the $\mathrm{I} / \mathrm{R}$ alone. The activity of these enzymes was different from the control values by 7.4 and 4.8 times, respectively. This highlights a further progression of cytolysis and output of enzymes from the damaged hepatic tissue as a result of L-NAME pre-treatment.

Therefore, it was found that stimulation of NO synthesis in the animals with $\mathrm{l} / \mathrm{R}$ improved function of the liver and blockage of NO synthesis by nonselective NOS inhibitorL-NAME aggravates liver injury.

Stimulated iNOS activity was registered in $\mathrm{I} / \mathrm{R}$ treatment, content of which in the liver increased by $57.6 \%$, while in the serum - by $185.0 \%$. Whereas, the concentration of eNOS in the liver was reduced by $38.5 \%$ and in the blood by $18.2 \%$ compared with the group 1 (Table 2).
These changes took place on the background of a decline in serum levels of stable metabolite of nitric oxide $\mathrm{NO}_{2}^{-}$by $51.7 \%$. This value has not changed significantly in the liver relative to the control group of similar animals. The level of $\mathrm{NO}_{3}^{-}$in the blood did not change significantly compared to the liver where it was reduced by $65.5 \%$ (Table 3 ). Quantitative indicators can be evaluated as a manifestation of a decrease in the total content of final metabolites of $\mathrm{NO}$ in both blood and liver during I/R trial.

The intensity of metabolism of nitric oxide under conditions of prophylactic administration of its precursor was evaluated by the concentration of its stable metabolites (Table 3 ) and the activity of NOsynthase isoforms (Table 2).

The level of nitric oxide metabolites in the blood increased: $\mathrm{NO}_{2}^{-}-$by 3.7 times, and $\mathrm{NO}_{3}^{-}-$by $31.7 \%$, respectively, after administration of L-arginine, and in liver homogenates the content of nitrite anion was not changed $(p>0.05)$, and the nitrate anion increased respectively by 3.1 times.

We observed one-way influence of the substance on the expression of NO-synthase isoforms, both in blood and in the liver. Enzyme immunoassay results showed that the use of L-arginine in $\mathrm{I} / \mathrm{R}$ treatment leads to increased eNOS content in hepatocytes $(43.5 \%)$ and the reduction of iNOS (19.2\%) (Table 2). A similar pattern was observed

Table 1. Effect of L-arginine on ALT and AST activity in the liver of sham and experimental groups of rats

\begin{tabular}{|c|c|c|c|c|}
\hline Data & Sham & I/R injury & L-arginine +l/R (group & $\begin{array}{c}\text { L-NAME+l/R } \\
\text { (group 4) }\end{array}$ \\
\hline ALT & (group 2) & 3) & $3.25 \pm 0.12$ \\
& $0.44 \pm 0.10$ & $2.35 \pm 0.09$ & $1.10 \pm 0.09$ & $p<0.001$ \\
& & $p<0.001$ & $p_{0}<0.005$ & $p_{1}<0.001$ \\
\hline AST & $1.63 \pm 0.12$ & $4.27 \pm 0.37$ & $2.83 \pm 0.20$ & $7.87 \pm 0.15$ \\
& & $p<0.001$ & $p<0.01$ & $p<0.001$ \\
& & & $p_{1}<0.05$ & $p_{1}<0.001$ \\
\hline
\end{tabular}

Results are expressed as mean $\pm S D(n=6)$; significantly different: $p$ - from sham, $p_{1}$ - from I/R injury group; activity of ALT and AST are expressed in $\mathrm{mmol} /\left(\mathrm{I}^{\prime} \mathrm{h}\right)$

Table 2. eNOS and iNOS content in liver and blood of sham and experimental groups

\begin{tabular}{|c|c|c|c|c|}
\hline \multirow[b]{2}{*}{ Groups } & \multicolumn{2}{|c|}{ Blood } & \multicolumn{2}{|c|}{ Liver } \\
\hline & $\begin{array}{l}\text { eNOS } \\
\mathrm{U} / \mathrm{ml}\end{array}$ & $\begin{array}{l}\text { iNOS } \\
\mathrm{ng} / \mathrm{ml}\end{array}$ & $\begin{array}{c}\text { eNOS } \\
\text { U/ml } \\
\left(1 \mathrm{ml}-1 \times 10^{6} \text { cells }\right)\end{array}$ & $\begin{array}{c}\mathrm{iNOS} \\
\mathrm{ng} / \mathrm{ml} \\
\left(1 \mathrm{ml}-1 \times 10^{6} \text { cells }\right)\end{array}$ \\
\hline Sham (group 1) & $3.18 \pm 0.17$ & $24.95 \pm 0.97$ & $7.95 \pm 0.60$ & $2.68 \pm 0.16$ \\
\hline I/R (group 2) & $\begin{array}{c}2.60 \pm 0.14 \\
p<0.05\end{array}$ & $\begin{array}{c}71.22 \pm 4.01 \\
p<0.001\end{array}$ & $\begin{array}{c}4.86 \pm 0.24 \\
p<0.001\end{array}$ & $\begin{array}{c}4.22 \pm 0.16 \\
p<0.001\end{array}$ \\
\hline $\begin{array}{l}\mathrm{L}-\operatorname{arginine}+\mathrm{I} / \mathrm{R} \\
\text { (group 3) }\end{array}$ & $\begin{array}{c}3.50 \pm 0.24 \\
p>0.1 \\
p_{1}<0.05\end{array}$ & $\begin{array}{c}53.54 \pm 1.74 \\
p<0.001 \\
p_{1}<0.001\end{array}$ & $\begin{array}{c}6.98 \pm 0.17 \\
p>0.1 \\
p_{1}<0.001\end{array}$ & $\begin{array}{c}3.41 \pm 0.14 \\
p<0.05 \\
p_{1}<0.001\end{array}$ \\
\hline $\begin{array}{l}\text { L-NAME+I/R } \\
\text { (group 4) }\end{array}$ & $\begin{array}{l}1.14 \pm 0.12 \\
p<0.001 \\
p_{1}<0.001\end{array}$ & $\begin{array}{c}31.40 \pm 1.61 \\
\mathrm{p}<0.001 \\
\mathrm{p}_{1}<0.001\end{array}$ & $\begin{array}{c}2.99 \pm 0.20 \\
p<0.001 \\
p_{1}<0.001\end{array}$ & $\begin{array}{c}2.56 \pm 0.06 \\
p>0.1 \\
p_{1}<0.001\end{array}$ \\
\hline
\end{tabular}

For this and for the following table the results are expressed as mean $\pm S D(n=6)$; significantly different: $p$ - from sham, $p_{1}$ from I/R injury group 
Table 3. $\mathrm{NO}_{2}^{-}$and $\mathrm{NO}_{3}{ }^{-}$content in liver and blood of sham and experimental groups

\begin{tabular}{|l|c|c|c|c|}
\hline \multirow{2}{*}{ Groups } & \multicolumn{2}{|c|}{ Blood } & \multicolumn{2}{c|}{ Liver } \\
\cline { 2 - 5 } & $\begin{array}{c}\mathrm{NO}_{2}^{-}, \\
\mathrm{micromol} / \mathrm{l}\end{array}$ & $\begin{array}{c}\mathrm{NO}_{3}^{-}, \\
\text {micromol/l }\end{array}$ & $\begin{array}{c}\mathrm{NO}_{2}^{-}, \\
\text {micromol } / \mathrm{kg}\end{array}$ & $\begin{array}{c}\mathrm{NO}_{3}^{-}, \\
\text {micromol } / \mathrm{kg}\end{array}$ \\
\hline Sham (group 1) & $1.62 \pm 0.08$ & $10.18 \pm 0.41$ & $1.70 \pm 0.11$ & $9.29 \pm 0.59$ \\
\hline I/R (group 2) & $0.78 \pm 0.05$ & $9.90 \pm 0.46$ & $1.67 \pm 0.16$ & $3.20 \pm 0.77$ \\
& $\mathrm{p}<0.001$ & $\mathrm{p}>0.05$ & $\mathrm{p}>0.05$ & $\mathrm{p}<0.001$ \\
\hline L-arginine+l/R & $2.84 \pm 0.07$ & $13.05 \pm 0.63$ & $2.07 \pm 0.10$ & $9.94 \pm 0.60$ \\
(group 3) & $\mathrm{p}<0.001$ & $\mathrm{p}<0.01$ & $\mathrm{p}>0.05$ & $\mathrm{p}>0.05$ \\
& $\mathrm{p}_{1}<0.001$ & $\mathrm{p}_{1}<0.01$ & $\mathrm{p}_{1}>0.05$ & $\mathrm{p}_{1}<0.001$ \\
\hline L-NAME+l/R & $0.43 \pm 0.04$ & $8.65 \pm 0.12$ & $0.98 \pm 0.03$ & $1.73 \pm 0.07$ \\
(group 4) & $\mathrm{p}<0.001$ & $\mathrm{p}<0.05$ & $\mathrm{p}<0.001$ & $\mathrm{p}<0.05$ \\
& $\mathrm{p}_{1}<0.01$ & $\mathrm{p}_{1}<0.05$ & $\mathrm{p}_{1}<0.05$ & $\mathrm{p}_{1}>0.05$ \\
\hline
\end{tabular}

in blood. Inducible NO-synthase was reduced by $24.8 \%$ after the use of L-arginine, but remained higher by more than 2.1 times, compared with sham group of animals. Endothelial isoform of the enzyme increased by $34.5 \%$ compared to its value in group 1. To summarize, we can say that prophylactic administration of NO precursor L-arginine before l/R was followed by the activation of a constitutive NOsynthase, with a simultaneous decrease of inducible NOS activity and increase in nitric oxide metabolites level.

It is logical that the expression of both isoforms of nitric oxide synthase, on the background of inhibition ofL-NAME, decreased eNOS content was even lower than in the group of animals without correction by 56.5 and $38.5 \%$, and the expression of iNOS decreased by 55.9 and $39.3 \%$ in blood and hepatocytes.

Therefore, L-NAME reduced expression of all NOS forms (Table 2). It was also shown that the level of nitrite and nitrate anions after administration of non-selective blocker of NO synthesis decreased by 45.0 and $12.6 \%$ in the serum and by 41.1 and $46.0 \%$ in liver homogenates compared to IR. The levels were also significantly lower in the affected organ (by 1.7 and 1.8 times) compared to the group

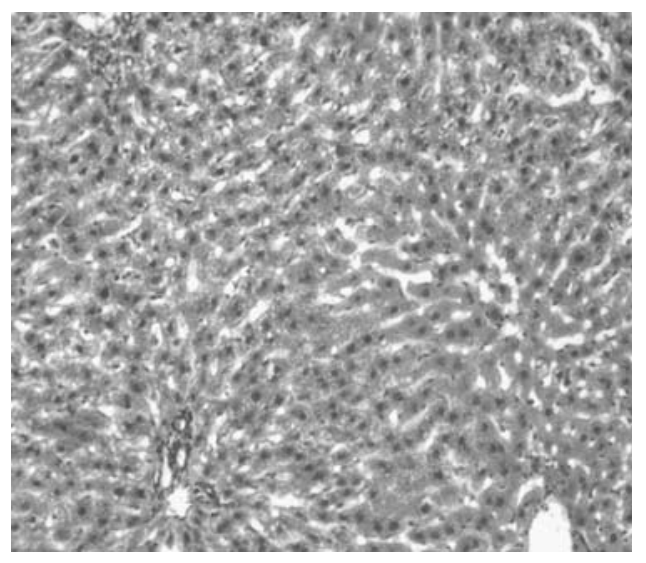

Fig. 1. Histological structure of the liver after administration of L-arginine in ischemia-reperfusion injury. Hematoxylineosin. Magnification power 160×.
1 of animals. We can hypothesize that reduction of end metabolites of nitric oxide synthesis correlates with inhibition of NO synthase expression in both serum and liver (Table 3).

During histological examination of liver tissue of animals, which previously were administered Larginine and subsequently simulated ischemiareperfusion, we found that the trabecular structure of the liver lobules was preserved. The central veins were dilated and well visualized. Periportal areas had lymphocytic and histiocytic infiltration, particularly around the bile duct (Fig.1).

Histological examination of liver tissue in ischemia-reperfusion model on the background of the previousL-NAME administration showed that the trabecular structure of the liver lobules was significantly changed (Fig. 2).

Sinusoids were greatly expanded and they were free from red blood cells in central lobular areas. Narrowed and saturated cell macrophages in the central and peripheral parts of the liver lobules were not present as well. Portal tracts expanded mainly due to the plethora of vessels and severe perivascular lymphocytic and histiocytic infiltration. Signs of small droplets of fat and protein degeneration were present. Enhanced bile ducts and the presence of a

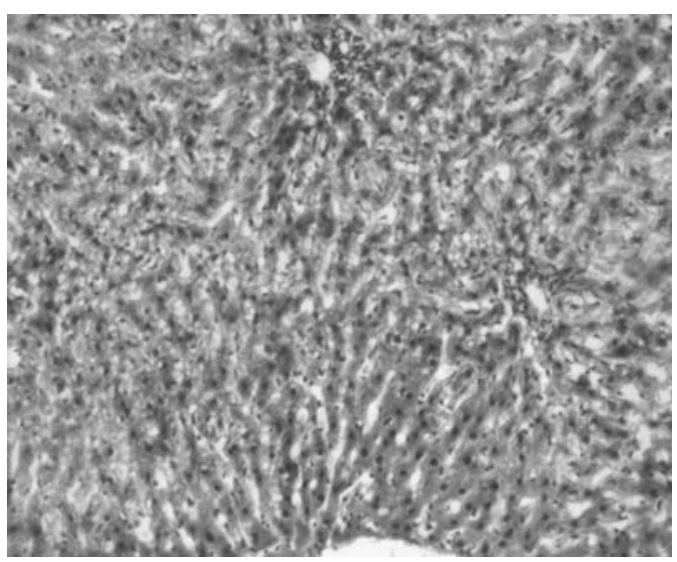

Fig. 2 Histological structure of the liver during ischemiareperfusion and application of L-NAME. Hematoxylin-eosin. Magnification power $160 \times$. 
small amount of bile can be estimated as intrahepatic cholestasis. A large number of cells with pyknotic nuclei and necrotic cells were observed during histological observation in periportal zone of acinus.

\section{Discussion}

$\mathrm{I} / \mathrm{R}$ is a series of multifaceted cellular events which take place on the resumption of oxygen delivery to the affected organ after a period of hypoxia. IR occurs in the liver during procedures that are associated with vascular inflow obstruction followed by restoration of blood flow. I/R may result in major hepatocellular damage [8].

NO plays a significant role in the acute phase of $\mathrm{I} / \mathrm{R}$, as this phase is associated with a rapid decrease in available NO. This decrease occurs either by depressed production by eNOS in sinusoidal endothelial cells, increased degradation by reactive oxygen species, or both [9]. In this I/R study expression of liver iNOS increased and eNOS level decreased. It was determined during our previous $\mathrm{I} / \mathrm{R}$ studies that the levels of IL-1 $\beta$, IL- 6 and TNF- $\alpha$ in I/R were significantly increased [6]. Therefore, cytokines provoked stimulation of iNOS expression. To summarize, there is a lack of synthesis of NO during the early periods of reperfusion, which may be due to inhibition of eNOS [9]. As for this study, we have found that after 2 hours of reperfusion levels of nitrates do not change significantly in the blood with decrease in the liver, and conversely decreased blood nitrite levels.

We have shown that the application of $\mathrm{L}$-arginine during $\mathrm{I} / \mathrm{R}$ trial causes activation of nitric

\section{References}

1. Selzner N, Rudiger H, Graf R, Clavien P. Protective strategies against ischemic injury of the liver. Gastroenterol 2003; 125: 917-936.

2. Bahde H, Spiegel HU. Hepatic ischemia-reperfusion injury from bench to bedside. Bri J Surg 2010; 97: 1461-1475.

3. Ohmori H, Dhar D, Nakashima Y et al. Beneficial effects of FK409, a novel nitric oxide donor on reperfusion injury of rat liver. Transplantation 1998; 66: 579-585.

4. Shah V, Kamath SP. Nitric oxide in liver transplantation: pathobiology and clinical implication. Liver Transplantation 2003; 1 (9): 1-11.

5. Lin HI, Wang D, Leu F-J. et al. Ischemia and reperfusion of liver induces eNOS and iNOS expression: effects of NO donor and NOS inhibitor. Chin J Physiol 2004: 47 (3): 121-127.

6. Oleshchuk OM. Experimental study of nitric oxide precursors in hepatic ischemia-reperfusion. Hospital surgery 2012; 4(60): 42-47. (in Ukrainian)

7. Kiselyk IO, Lutsyk MD, ShevchenkoLYu. Features determination of nitrate and nitrite in the blood of patients oxide synthesis. Increased concentrations of $\mathrm{NO}$ stable metabolites nitrite and nitrate anions in both blood and liver is consistent with our previous results and other scientific data $[10,11]$. We observed oneway impact on the content of NO-synthase isoform in blood and in the liver. The level of endothelial form increased and inducible - declined. Results of our histological studies have shown that the precursor of nitric oxide synthesis has protective influence on the morphological structure of hepatocytes.

Blocking the enzymatic synthesis of $\mathrm{NO}$ in liver $\mathrm{I} / \mathrm{R}$ led to the aggravation of the pathological process, as evidenced by the results of our biochemical and histological studies.

Thus, the introduction of non-selective blocker of NOSL-NAME increased activity of ALT and AST, indicating a further increase cytolysis of hepatocytes and this is consistent with L. M. Wang et al. (2003) [12]. Our results on the liver degradation by complete blocking enzymatic NO formation during l/R suggest NO protective role during early reperfusion.

\section{Conclusion}

Ischemia reperfusion injury is a well-defined threat to the liver during periods of interruption and restoration of oxygen delivery. It occurs in certain procedures such as hepatic resections and orthotopic liver transplantation. Relative NO deficiency, due to eNOS inhibition, is central in the pathogenesis of this injury. Replacing NO per se either precursors or via donor drugs represents a novel method for ameliorating hepatic ischemiareperfusion injury. with viral hepatitis and jaundice of different etiology. Lab diagnostyka 2001; 3: 43-45. (in Ukrainian)

8. Phillips L, Lopez-Neblina F, Toledo-Pereyra LH. Nitric oxide mechanism of protection in ischemia and reperfusion injury J Invest Sur 2009; 22: 46-55.

9. Hines IN, Kawachi S, Harada $\mathrm{H}$ et al. Role of nitric oxide in liver ischemia and reperfusion injury. Mol Cell Biochem 2002; 234/235: 229-237.

10. Chattopadhyay P, Shukla G, WahiAK. Protective effect of $L$-arginine against necrosis and apoptosis induced by experimental ischemic and reperfusion in rat liver. Saudi J Gastroenterol 2009; 15 (3): 156-162.

11. Chander V, Chopra K. Renal protective effect of molsidomine and $\mathrm{L}$-arginine in ischemia-reperfusion induced injury in rats. J Surg Res 2005; 128: 132-139.

12. Wang LM, Tian XF, Song QY et al. Expression and role of inducible nitric oxide synthase in ischemiareperfusion liver in rats. Hepatobiliary Pancreat Dis Int 2003; 2: 252-258. 